\title{
Ciclos integradores no pet-saúde graduasus: experiência de integração interprofissional e repercussões na reflexão da integração ensino-serviço-comunidade e mudanças curriculares
}

\author{
Érica Cesário Defilipo, Lélia Cápua Nunes, Nízia Araújo Vieira Almeida, Mabel Miluska Suca
}

Salas, Pedro Henrique Berbert de Carvalho

\section{Resumo}

Introdução: A integração interprofissional em saúde é uma estratégia de trabalho colaborativo em equipe, na qual a convivência em cenários de prática comuns entre as diferentes profissões pode permitir o desenvolvimento da clínica ampliada, o processo de comunicação e tomadas de decisão compartilhadas para a melhor resolutividade do cuidado em saúde. A atuação interprofissional repercute na educação, uma vez que reforça a necessidade de formação de profissionais capacitados e treinados para o trabalho em equipes que fortaleçam a concepção de cuidado integral, a partir das vivências e práticas de saúde concebidas por meio de processos dialógicos e coletivos. No processo formativo que permite a convivência contínua entre as diversas áreas, há o compartilhamento de situações reais das quais elas participam, compactuação, trocas de saberes, construção e ressignificação de conceitos pré-estabelecidos, o que amplia a inter-relação entre teoria e prática, a relação de parceria de trabalho comum entre os atores deste processo e a autonomia de todos os envolvidos (AZEVEDO; PEZZATO; MENDES, 2017). O PET- Saúde/GraduaSUS da UFJF/GV criou e implementou os ciclos integradores, na perspectiva de trabalhar o eixo da reestruturação curricular de acordo com as novas Diretrizes Curriculares Nacionais, e favorecer a inserção das vivências nos cenários de prática, potencializadas pela integração ensino-serviço-comunidade, nos currículos dos cursos da área da saúde. Objetivos: Este trabalho tem como objetivo relatar a experiência de integração interprofissional, por meio de vivências nomeadas "ciclos integradores" realizadas no Programa de Educação pelo Trabalho para a Saúde - PET-Saúde GraduaSUS da Universidade Federal de Juiz de Fora - Campus Governador Valadares (UFJF-GV), e narrar suas repercussões na reflexão da integração ensino-serviço-comunidade e mudanças curriculares. Métodos: O presente estudo caracteriza-se como um relato de experiência (DYNIEWICZ, 2014). Surge após observação sistemática, descrição e análise da realidade vivenciada pelos integrantes do Programa de Educação pelo Trabalho para a Saúde - PET- Saúde GraduaSUS da Universidade Federal de Juiz de Fora - Campus Governador Valadares (UFJF-GV). Em parceria com a Secretaria de Saúde do Município de Governador Valadares a Universidade foi contemplada com 50 bolsas para o projeto a ser desenvolvido entre o período de maio/2016 a maio/2018 (Edital nº 13 de 28 de setembro de 2015). Foram definidos como objetivos da proposta apresentada a integração ensinoserviço-comunidade e ainda, a promoção de mudança curricular alinhada às Diretrizes Curriculares Nacionais para os cursos de graduação da área da saúde (BRASIL, 2015). Participam deste projeto discentes e docentes dos cursos de Educação Física, Farmácia, Fisioterapia, Medicina, Nutrição e Odontologia da UFJF-GV, além de preceptores, profissionais de saúde inseridos nos serviços de atenção à saúde do município de Governador Valadares (Minas Gerais, Brasil). Dentre as atividades propostas no Projeto, foram planejados os "Ciclos Integradores" para todos os partícipes do projeto: estudantes, docentes como os tutores e os profissionais de saúde do serviço, como preceptores, totalizando 90 integrantes. Os "Ciclos Integradores" oportunizaram o debate de temas de interesse à formação em saúde e exercício das atividades nos cenários de vivência dos grupos tutoriais. Foram realizados seis ciclos integradores, a cada dois meses com foco nos seguintes eixos: 
ISSN 2179-6750

"Interface ensino-serviço- comunidade", "Planejamento Estratégico Situacional", "Níveis de atenção à saúde: Atenção primária em foco", "Controle Social", "Redes de Atenção à Saúde" e "Realidades vivenciadas nos cenários de prática". Todos os ciclos utilizaram técnicas e metodologias ativas, como a Aprendizagem Baseada em Equipes, Aquário, Café Mundial e a Problematização. Os participantes sempre compunham grupos heterogêneos, com integrantes de diferentes grupos tutoriais e de atribuições (tutores, preceptores e estudantes), com debates baseados em seus contextos de trabalho, no estímulo à reflexão crítica e na aplicação nos cotidianos de serviço de saúde e instituição de ensino. Resultados e Discussão: As metodologias de ensino como estratégias ativo-problematizadoras, estão apoiadas em um princípio teórico significativo de autonomia. Em conexão com o processo formativo dos cursos de saúde, o uso de estratégias construtivistas de ensino e aprendizagem traz sua intencionalidade alicerçada em uma formação capaz de desenvolver no discente a competência de aprender a aprender, englobando neste movimento o conhecer, o fazer, o viver junto e, sem dúvidas, o aprender a ser. Desta forma, é possível garantir aos futuros profissionais da saúde, a capacitação da autonomia e do discernimento para assegurar a integralidade da atenção à saúde com eficiência, eficácia e, principalmente, de forma contextualizada e humanizada. Foi observado que os ciclos integradores promoveram a participação ativa dos integrantes de todos os grupos tutoriais, motivando e incentivando a interação multiprofissional por meio de reflexão sobre teoria e vivências no campo de atuação da atenção primária, baseada em problemáticas reais. A discussão entre integrantes de diversas áreas ampliaram e enriqueceram a construção e o entendimento da importância da efetivação do enlace ensinoserviço-comunidade em prol da consolidação do SUS e em consonância direta com as reais necessidades em saúde da população brasileira, como: planejamento em saúde como estratégia de potencialização das ações das equipes de saúde; redes de atenção e a atenção primária como componente e porta de entrada das redes, visando a integralidade da assistência; além do controle social para intervenção nas ações de saúde e consequentemente no processo saúde doença. A metodologia realizada em todos os ciclos integradores por equipes multiprofissionais contribuíram com a vivência do trabalho não fragmentado, integrado e compartilhado entre as diversas áreas do saber, pautado em relações sociais horizontais, de escuta atenta, respeito da opinião e pensar do outro, aprendendo novos conhecimentos e dinâmicas de atuação que implicam o compartilhar do planejamento, divisão de tarefas, cooperação e colaboração. Adicionalmente, foi possível observar que as atividades baseadas em métodos ativos permitiram o desenvolvimento de habilidades de autonomia e crítica reflexiva, assim como a geração de inquietudes entre os participantes, objetivando atitudes de responsabilidade e compromisso social, as quais culminaram no desenvolvimento de estratégias de intervenção e possibilidades de (re)pensar transformações no cotidiano dos serviços e da academia. Conclusão: Considerando o relato e as articulações teóricometodológicas apresentadas, é possível afirmar que a experiência contribuiu substancialmente para a formação do grupo no que tange os desafios encontrados nas atividades práticas do projeto em campo e os conteúdos abordados de forma transversal na execução das ações de planejamento e intervenção em serviço. As práticas integrativas inseridas na interface ensino-serviço em saúde permitiram a troca de conhecimento entre os estudantes, docentes e preceptores promovendo uma abrangência maior de conhecimentos. A formação de grupos tutoriais interprofissionais permitiu um vasto campo de interlocuções e o ciclo integrador resultou no aprimoramento profissional dos preceptores e tutores e no aperfeiçoamento da formação dos estudantes, além de possibilitar profundas reflexões acerca do processo de trabalho em saúde inserido também no cenário das diretrizes curriculares nacionais.

Descritores: Relações interprofissionais, aprendizado ativo, educação em saúde, instituições acadêmicas. 